\title{
Obesity hormone leptin induces growth and interferes with the cytotoxic effects of 5 -fluorouracil in colorectal tumor stem cells
}

\author{
Monica Bartucci, Susanne Svensson ${ }^{1}$, Lucia Ricci-Vitiani, \\ Rosanna Dattilo', Mauro Biffoni, Michele Signore, Rita Ferla ${ }^{3}$, \\ Ruggero De Maria and Eva Surmacz ${ }^{3}$
}

\author{
Department of Hematology, Oncology and Molecular Medicine, Istituto Superiore di Sanità, 00161 Rome, Italy \\ ${ }^{1}$ Scuola Superiore di Catania, Università di Catania, 95100 Catania, Italy \\ ${ }^{2}$ Faculty of Medicine, University of Tor Vergata, 00173 Rome, Italy \\ ${ }^{3}$ Sbarro Institute for Cancer Research and Molecular Medicine, Temple University, Philadelphia, Pennsylvania 19122, USA \\ (Correspondence should be addressed to E Surmacz; Email: surmacz@temple.edu)
}

\begin{abstract}
The incidence of colon cancer has increased in developed countries, possibly due to sedentary lifestyle and high caloric diet. Experimental and epidemiological evidence suggests a link between colon cancer development and adipose tissue-derived circulating hormones. Leptin, a pluripotent cytokine secreted by adipocytes, is a key regulator of appetite and energy balance acting in the brain. On the other hand, leptin also controls many physiological and pathological processes in peripheral organs. Recent studies in colon cancer cell lines and human tumors suggested that leptin and its receptor (ObR) are implicated in colon carcinogenesis, and may serve as new biomarkers and pharmacological targets. Here, we explored, for the first time, whether leptin can affect the biology of colorectal tumor stem cells (CTSCs). We found that our previously established and characterized CTSC clones express ObR and respond to leptin with cell proliferation, activation of the extracellular signal-related kinase (ERK)1/2 and AKT signaling pathways, enhanced growth in soft agar, and improved sphere formation associated with E-cadherin overexpression. Moreover, leptin counteracted cytotoxic effects of 5-fluorouracil, a common colon cancer therapeutic agent. These results suggest that obesity and increased leptin levels might promote colorectal cancer by increasing growth and survival of CTSCs.
\end{abstract}

Endocrine-Related Cancer (2010) 17 823-833

\section{Introduction}

Colorectal cancer is one of the most common neoplasms in the western world (Wilmink 1997, Jemal et al. 2006). A large body of epidemiological evidence suggests that obesity increases colorectal cancer risk by 0.4 - to 1.0 -fold in men and up to 2.0 -fold in premenopausal women (Calle \& Thun 2004, Renehan et al. 2008). Although molecular mechanisms underlying this association are still unclear, in vitro data suggested direct involvement of fat tissue in colon cancer development. Indeed, adipocytes and preadipocytes can stimulate the growth of colon cancer cells (Amemori et al. 2007). Furthermore, biologically active substances produced by adipocytes, such as cytokines (especially pro-inflammatory), growth factors, steroid hormones can exert oncogenic effects in the large bowel (Karagiannides \& Pothoulakis 2007, Pischon et al. 2008, Pais et al. 2009).

The principal hormone synthesized by adipocytes is leptin. In humans, circulating leptin levels correlate with body mass index, and are significantly elevated in obese individuals (Wauters et al. 2000, Zhang et al. 2005). Leptin was originally discovered as a neurohormone controlling feeding behavior and energy homeostasis. However, later studies proved that leptin is a pleiotropic cytokine involved in a great variety of 
physiological and pathological processes in peripheral organs (Wauters et al. 2000). Recent data clearly indicate that leptin, due to its mitogenic, antiapoptotic, pro-inflammatory, and angiogenic properties can promote development and progression of different cancer types (Garofalo \& Surmacz 2006).

During fetal development, locally produced leptin appears to regulate the growth and/or maturation of the digestive tract (Aparicio et al. 2005a). Postnatally, leptin modulates local immune responses, and has been shown to exert either pro- or anti-inflammatory activities in the intestine, depending on the experimental model (Siegmund et al. 2002, 2004, Bozkurt et al. 2003, Aparicio et al. 2004, Cakir et al. 2004, Sitaraman et al. 2004, Adeyemi et al. 2005, Karagiannides \& Pothoulakis 2007).

New evidence suggests that leptin can be implicated in colorectal cancer. Increased leptin levels, at least in some studies, have been associated with greater risk of colorectal cancer development, especially in males (Stattin et al. 2003, 2004). In human colorectal cancer tissues, but not in normal mucosa or adenomas, leptin and its receptor (ObR) are significantly overexpressed, and correlate with the proneoplastic transcriptional regulator, hypoxia-inducible factor 1 , and a more advanced tumor phenotype $\left(\mathrm{G}_{2}\right.$ grade; Koda et al. 2007a,b, Paik et al. 2009).

In colon epithelial cells, leptin can induce chemokine production associated with macrophage activation similar to that observed in an adenomatous polyposis coli genotype (Fenton et al. 2007, 2008). In vitro, leptin can stimulate DNA synthesis, enhance proliferation and survival (mostly through the ERK1/2 and phosphatidylinositol 3-kinase (PI3K)/AKT pathways) as well as promote migration and invasion in colorectal cancer cells (Attoub et al. 2000, Hardwick et al. 2001, Rouet-Benzineb et al. 2004, Jaffe \& Schwartz 2008, Ratke et al. 2010).

Colorectal cancer originates from epithelial cells lining the gastrointestinal tract that undergo sequential and specific DNA mutations disrupting normal mechanisms of proliferation. Stem cells of the gastrointestinal tract might be a principal target of tumorigenic mutations, due to their naturally long lifespan and capacity for self-renewal. The concept of stem cell-driven tumorigenesis in colorectal cancer is supported by the identification and phenotypic characterization of a subpopulation of colon cancer cells capable of initiation and faithful reproduction of human colon carcinomas in immunocompromised mice (tumor-initiating cells or colorectal tumor stem cells, CTSCs). Important screening characteristics of CTSC include the presence of cluster of differentiation
(CD)133, CD166, and Lgr5 antigens (labeling undifferentiated cells) and the lack of cytokeratin 20 (CK20), which is expressed only by differentiated progeny (Barker et al. 2007, 2009, Dalerba et al. 2007, O'Brien et al. 2007, Ricci-Vitiani et al. 2007, 2009). Previously, we developed tumor-derived clones that possess features of CTSCs, namely, they express CD133, lack CK20, and readily reproduce the original tumor in immunodeficient mice (Ricci-Vitiani et al. 2007). Here, we investigated whether our CTSCs express functional $\mathrm{ObR}$ and whether the obesity hormone leptin might affect their growth, survival, and tumorigenic properties in vitro.

\section{Materials and methods}

\section{Reagents}

Leptin was purchased from R\&D Systems, Inc. (Minneapolis, MN, USA), 5-fluorouracil (5-FU), and LY294002 from Sigma-Aldrich and U0126 from Promega.

\section{Cell culture of CTSCs}

The CTSC1.1, CTSC1.2, CTSC18, CTSC36, and CTSC85 clones were obtained from tumor samples of patients who underwent surgical resection of colon tumors, as described by us previously (Ricci-Vitiani et al. 2007). In brief, surgical specimens were washed several times and left overnight in DMEM:F12 medium supplemented with 500 Units/ml penicillin, $500 \mu \mathrm{g} / \mathrm{ml}$ streptomycin, and $5 \mu \mathrm{g} / \mathrm{ml}$ amphotericin B. Tissue dissociation was carried out by enzymatic digestion with $1.5 \mathrm{mg} / \mathrm{ml}$ collagenase II (GibcoInvitrogen) for $2 \mathrm{~h}$ at $37{ }^{\circ} \mathrm{C}$. Recovered cells were cultured at clonal density in a growth medium specifically adapted for CTSCs. The complete serumfree medium (SFM) for CTSCs consists of DMEM:F12 (Gibco-Invitrogen), supplemented with $50 \mu \mathrm{g} / \mathrm{ml}$ insulin, $100 \mu \mathrm{g} / \mathrm{ml}$ apo-transferrin, $10 \mu \mathrm{g} / \mathrm{ml}$ putrescine, $0.03 \mathrm{mM}$ sodium selenite, $2 \mu \mathrm{M}$ progesterone, $0.6 \%$ glucose, $5 \mathrm{mM}$ HEPES, $0.1 \%$ sodium bicarbonate, $0.4 \%$ BSA, 2 mM L-glutamine, 100 Units $/ \mathrm{ml}$ penicillin, $100 \mu \mathrm{g} / \mathrm{ml}$ streptomycin, $20 \mathrm{ng} / \mathrm{ml}$ epidermal growth factor (EGF), and $10 \mathrm{ng} / \mathrm{ml}$ basic fibroblast growth factor (bFGF). Nontreated, sterile polystyrene flasks for suspension cell cultures (Nunc, Thermo Fischer Scientific, Rochester, NY, USA) were used to reduce cell adherence and support growth as undifferentiated tumor spheres (Ricci-Vitiani et al. 2007). The medium was replaced or supplemented with fresh growth factors $(20 \mathrm{ng} / \mathrm{ml} \mathrm{EGF}$ and $10 \mathrm{ng} / \mathrm{ml} \mathrm{bFGF}$ ) twice a week, until cells started to grow as floating 
aggregates. Cultures were expanded by mechanical dissociation of spheres, followed by replating of single cells and residual small aggregates in complete fresh SFM. Flow cytometry was used to analyze the immunophenotype of the subpopulations. The CTSCs used in this study were clearly positive for CD133 and negative for CK20 (Ricci-Vitiani et al. 2007). The colorectal adenocarcinoma cell lines SW 480 and HT-29 (purchased from AATC, LGC Standards s.r.l., Milan, Italy) were cultured in RPMI 1640 medium (PAA Laboratories, Pasching, Austria).

\section{Cytofluorimetric cell staining}

Colon tumor spheres were dissociated, and cells were counted. A total of $10^{5}$ single cells were labeled with CD133/1-phycoerythrin (PE) antibody (Ab; Miltenyi Biotec, Bergisch Gladbach, Germany) and/or CD166-PE Ab (BD Bioscience, Franklin Lakes, NJ, USA). For Lgr5 staining, a total of $2 \times 10^{5}$ single cells were fixed with $2 \%$ paraformaldehyde for $20 \mathrm{~min}$ room temperature, and then permeabilized with $0.1 \%$ Triton $\mathrm{X}-100 / \mathrm{PBS}$ for $5 \mathrm{~min}$ at $4{ }^{\circ} \mathrm{C}$ before incubation with Lgr5-FITC Ab (Gene Tex Inc., Irvine, CA, USA). Expression profiles were acquired with a FACS Canto instrument using FACS Diva software (Becton Dickinson, Milan, Italy). IgG mouse-PE Ab (Beckman Coulter Inc., Brea, CA, USA) was used as a negative control for CD133 and CD166, and Alexa Fluor 488 goat anti-rabbit IgG was used as negative control for Lgr5. Data were analyzed with Flowjo software (www. flowjo.com, Flowjo, Ashland, OR, USA).

\section{Cell growth and viability}

CTSCs were seeded at 50000 cells $/ \mathrm{ml}$ in duplicates in a 12 -well plate and treated with leptin $(300 \mathrm{ng} / \mathrm{ml})$ for $96 \mathrm{~h}$, with readdition of leptin $(300 \mathrm{ng} / \mathrm{ml})$ after $48 \mathrm{~h}$. In viability experiments, leptin treatment was followed by a 72-h exposure to $60 \mu \mathrm{g} / \mathrm{ml} 5-\mathrm{FU}$. For AKT inhibition experiments, cells were pretreated with leptin $(300 \mathrm{ng} / \mathrm{ml})$ for $24 \mathrm{~h}$, then treated with LY294002 $(50 \mu \mathrm{M})$ for $2 \mathrm{~h}$, before being exposed to 5 -FU $(60 \mu \mathrm{g} / \mathrm{ml})$ for $48 \mathrm{~h}$. U0126, a specific inhibitor of mitogen-activated protein kinase kinase (MEK)1/2, was used to block ERK1/2 activity. Cells were pretreated with U0126 $(5 \mu \mathrm{M})$ for $1 \mathrm{~h}$, and then treated with leptin $(300 \mathrm{ng} / \mathrm{ml})$ for $48 \mathrm{~h}$. Cell proliferation in control and treated cells was evaluated by collecting, dissociating, and counting cells with Trypan blue exclusion method or using 3-(4,5-dimethylthiazol-2yl)-2,5-diphenyltetrazolium bromide (MTT) assay. All data are a mean of three independent experiments.

\section{Western blot}

CTSCs were treated with leptin $(300 \mathrm{ng} / \mathrm{ml})$ for $96 \mathrm{~h}$, with readdition of leptin $(300 \mathrm{ng} / \mathrm{ml})$ after $48 \mathrm{~h}$. In some experiments, leptin treatment was followed by a 72-h exposure to $60 \mu \mathrm{g} / \mathrm{ml} 5$-FU. Whole cell lysates from treated cells were prepared in $1 \% \mathrm{NP} 40,20 \mathrm{mM}$ Tris (pH 7.2), $200 \mathrm{mM} \mathrm{NaCl}$, Phosphatase Inhibitor Cocktail 1 (used 1:100, P2850, Sigma-Aldrich), Phosphatase Inhibitor Cocktail 2 (used 1:100, P5726, Sigma-Aldrich), and Protease Inhibitor Cocktail (used 1:100, P8340, Sigma-Aldrich). The expression of proteins was assessed in $20 \mu \mathrm{g}$ of protein extracts with specific Abs: for ObR, H300 (Santa Cruz Biotechnology, Santa Cruz, CA, USA), for total ERK1/2, K-23 (Santa Cruz Biotechnology), for phosphorylated ERK1/2, E-4 (Santa Cruz Biotechnology), for phosphorylated AKT (Ser473), 193H12 (Cell Signaling Technology, Danvers, MA, USA), and for E-cadherin, 36/E-Cad (BD Bioscience, San Jose, CA, USA). Protein loading was assessed by measuring the expression of $\beta$-actin, using AC-15 Ab (Sigma-Aldrich), or $\beta$-tubulin, using TUB 2.1 Ab (Sigma-Aldrich).

\section{Apoptosis assay (TUNEL staining)}

This assay utilized terminal deoxynucleotidyl transferase dUTP nick end labeling (TUNEL) staining. Following treatments, CTSC spheroids and single cells were attached to poly-L-lysine coated coverslips by sedimentation, fixed with $2 \%$ paraformaldehyde, and permeabilized with $0.5 \%$ Triton X-100 overnight at $4{ }^{\circ} \mathrm{C}$. Apoptosis was determined with the In Situ Cell Death Detection kit, Fluorescein, following the manufacturer's instructions (Roche). Cells containing DNA strand breaks were stained with fluoresceindUTP, and 4',6-diamidino-2-phenylindole was used to visualize cell nuclei. Slides were analyzed using Olympus FV-1000 confocal microscope with the Olympus objective Ultraplan Apochromatic 60X N.A.1.35 and the software Olympus Fluoview (Olympus, Center Valley, PA, USA).

\section{Migration/chemoattraction assay}

Migration of CTSCs in response to leptin was evaluated in 24-well transwell chambers with upper and lower culture compartments separated by polycarbonate membranes with $8-\mu \mathrm{m}$ sized pores (3422, Corning Inc., Lowell, MA, USA). Single CTSCs suspended in $200 \mu \mathrm{l}$ of complete SFM were placed into upper chambers (10 000 cells/chamber), while complete SFM supplemented with $300 \mathrm{ng} / \mathrm{ml}$ leptin was placed into bottom chambers to act as a 
chemoattractant. After 48 or $96 \mathrm{~h}$ of incubation at $37^{\circ} \mathrm{C}$, the cells remaining on the upper surface of the membrane were removed with a cotton swab. The cells that migrated through pores and adhered to the lower surface of the membrane were stained with Coomassie Brilliant Blue and counted under the microscope.

\section{Soft agar assay}

CTSCs (1000 cells/well) were plated in 24-well plates containing a soft agar bilayer $(0.3 \%$ top and $0.4 \%$ bottom layer, SeaPlaque Agarose, Cambrex, East Rutherford, NJ, USA), plain or supplemented with leptin $(300 \mathrm{ng} / \mathrm{ml})$. Cultures were incubated at $37^{\circ} \mathrm{C}$ for 21 days. Colonies were stained with crystal violet $(0.01 \%$ in $10 \% \mathrm{MetOH})$ and counted under the microscope. Average size of the colonies was calculated using ImageJ Software (http://rsb.info.nih. gov/ij). The experiments were done in triplicate.

\section{Statistical analysis}

The statistical significance of the results for leptin on cell growth, intracellular signaling, migration, and colony formation was evaluated by $t$-test. The statistical significance of the results for leptin interference with chemotherapeutics and signaling inhibitors was evaluated by ANOVA and Bonferroni post-tests. A $P$ value $<0.05$ was represented by a single asterisk, while three asterisks indicate $P<0.001$. All statistical analyses were performed using GraphPad Prism 4 (GraphPad Software Inc., La Jolla, CA, USA, www.graphpad.com).

\section{Results}

\section{Expression of stem cell markers on CTSCs}

CTSCs used in this study were extensively described by us previously and proved to express CD133 and lack the differentiation marker CK20 (Ricci-Vitiani et al. 2007). However, to further validate the undifferentiated status of all our CTSCs, we assessed the expression of CD133 as well as of other known markers of CTSCs: CD166 (Dalerba et al. 2007) and Lgr5 (Barker et al. 2007, Sato et al. 2009). Flow cytometry analysis with specific Abs proved that all our stem cell lines are positive for the expression of CD166, Lgr5, and CD133 (Fig. 1A).

\section{Human CTSCs express ObR}

Leptin exerts its biological functions through binding to ObR. The long form of ObR (130-190 kDa) mediates downstream signals by activating multiple signaling pathways, while short forms of ObR have limited or no signaling capabilities (Ahima \& Osei 2004). To study the possible effects of leptin on CTSCs, we first examined the expression of ObR in five different clones of colon tumor stem cells. Western blot analysis demonstrated that all our cell lines expressed the long form of ObR. The highest levels of ObR were found in CTSC36 and CTSC1.2, while lower levels were noted in CTSC1.1, CTSC18, and CTSC85 (Fig. 1B). The colon cell lines SW 480 and HT-29, known to express ObR (Rouet-Benzineb et al. 2004, Aparicio et al. $2005 b$ ), were included as positive controls.

\section{Leptin stimulates proliferation of CTSCs through the activation of the ERK1/2 signaling pathway}

We tested leptin effects on the growth of CTSC1.1, CTSC1.2, CTSC18, and CTSC36 cells. The results indicated that leptin can stimulate proliferation of CTSCs expressing higher levels of ObR, but does not exert significant mitogenic activity in cells with low ObR expression. Leptin effects in CTCS36 and CTSC1.2 cells were evident at $96 \mathrm{~h}$ post treatment (Fig. 1C), and noticeable at $48 \mathrm{~h}$, but not at $24 \mathrm{~h}$ (data not shown).

To determine the intracellular signaling mechanisms responsible for leptin growth effects, we examined the activation of major postreceptor signaling pathways that are known to mediate ObR proliferation and survival effects in various cancer cell types, such as the ERK1/2 and AKT pathways (Fruhbeck 2006, Garofalo \& Surmacz 2006). An increased phosphorylation of ERK1/2 was observed in clones CTSC36 and CTSC1.2, and these effects coincided with elevated cell proliferation (Fig. 1C). To confirm the involvement of ERK1/2 signaling in leptin-induced cell growth, we inhibited ERK1/2 activity using U0126, a specific inhibitor of MEK1/2 (Favata et al. 1998). As demonstrated in Fig. 1D, blocking ERK1/2 completely abrogated leptin-enhanced cell growth, suggesting that the ERK1/2 pathway is responsible for the increased CTSC proliferation induced by leptin.

\section{Leptin activates PI3K/AKT signaling pathway and counteracts 5-FU-induced apoptosis in CTSCs}

Stimulation with leptin induced a moderate increase in phosphorylation of AKT in CTSC1.2 and CTSC36 expressing higher ObR levels, but had no effects in CTSC18 (Fig. 2A), characterized by low ObR expression. Activation of AKT signaling is known to promote cell survival and protection from apoptosis (Yang et al. 1997, Ozes et al. 1999). We investigated whether leptin has the ability to interfere with 

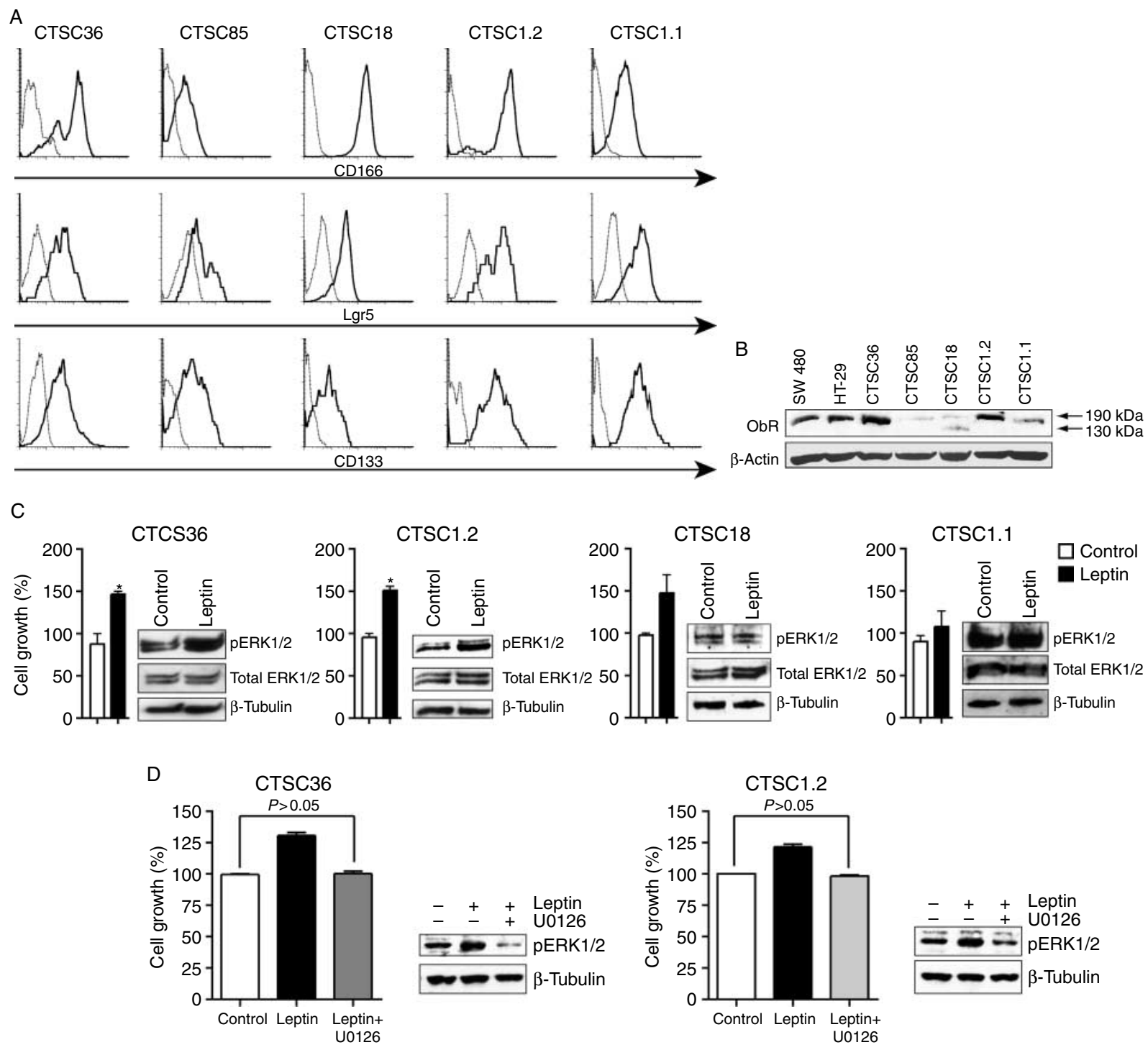

Figure 1 CTSCs express ObR, and leptin stimulates CTSCs growth through the activation of the ERK1/2 signaling pathway. (A) Analysis of stem cell markers in CTSC clones. The expression of CD133, CD166, and Lgr5 (heavy lines) was measured by FACS with specific Abs, as described in Materials and methods. Staining with control IgGs is indicated by dotted lines. (B) The expression of ObR in CTSC36, CTSC85, CTSC18, CTSC1.2, and CTSC1.1 was determined by western blotting as described in Materials and methods. Colorectal adenocarcinoma cell lines SW 480 and HT-29 were included as positive controls. A specific antibody against $\mathrm{ObR}$ was used to visualize the long form of ObR (130-190 kDa), and the expression of $\beta$-actin was used to verify protein loading. (C) Cell proliferation in the presence or in the absence of leptin was evaluated as described in Materials and methods. All data are a mean of three independent experiments. Leptin-induced ERK1/2 activation, total ERK1/2 levels, and $\beta$-tubulin expression (loading control) were determined by western blotting, as described in Materials and methods. (D) Involvement of the ERK1/2 signaling pathway in leptin-induced cell growth was assessed using the inhibitor U0126, as described in Materials and methods. All data are a mean of three independent experiments. The activation and expression of ERK1/2 was determined by western blotting using specific antibodies for phosphorylated ERK $1 / 2$ and total ERK $1 / 2$, as described in Materials and methods. $\beta$-Tubulin levels were assessed as loading control.

apoptotic effects of 5-FU in CTSCs. To this end, CTSC1.2, CTSC18, and CTSC36 were first exposed to leptin and thereafter treated with 5-FU. Cell viability assays demonstrated that leptin inhibited 5-FU-induced apoptosis in CTSCs expressing high levels of ObR, but was ineffective in CTSC18 containing low ObR levels (Fig. 2B). These observations were confirmed with the TUNEL assay, where leptin addition significantly reduced the occurrence of apoptotic cells in cultures treated with 5-FU (Fig. 2C). 
A
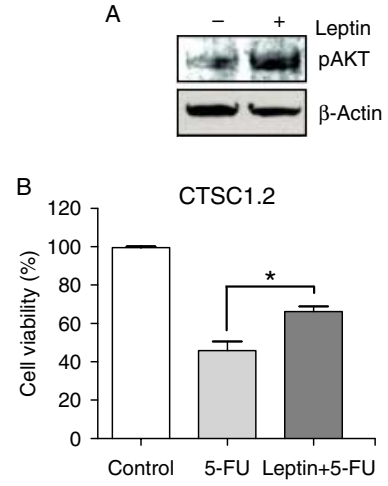

C

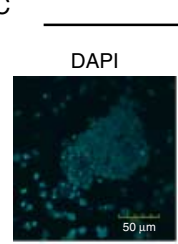

CTSC1.2
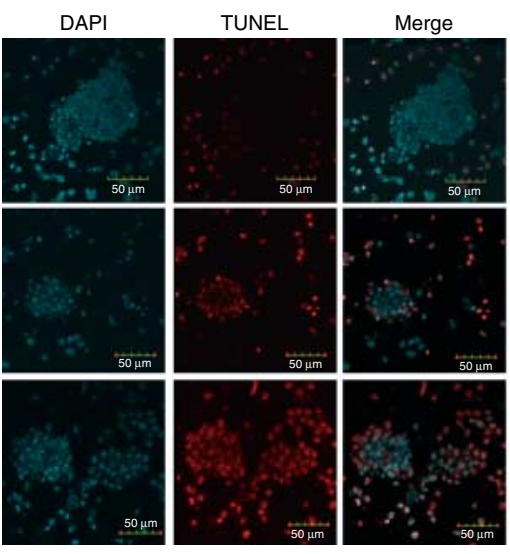
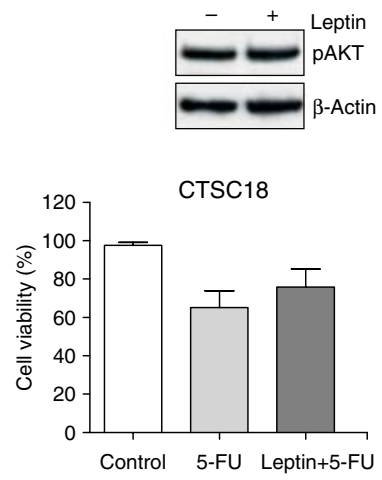
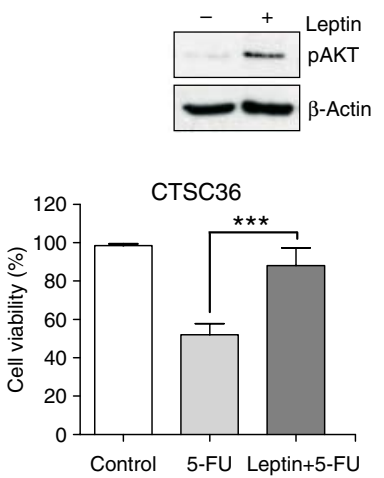

CTSC36

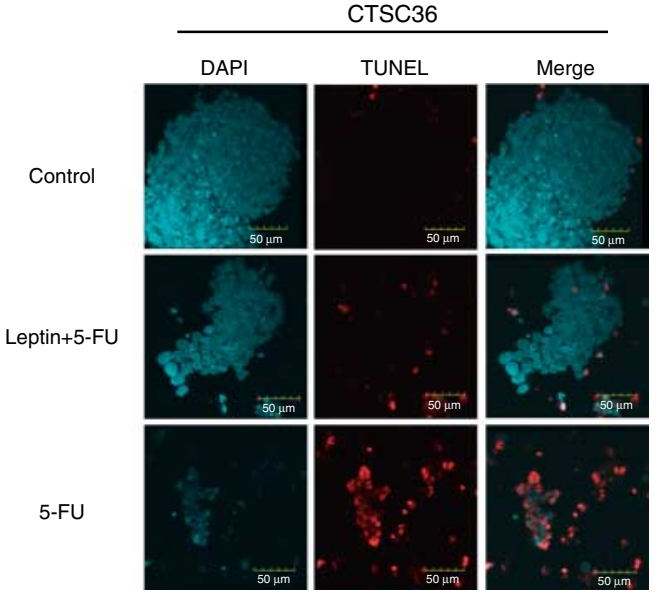

D

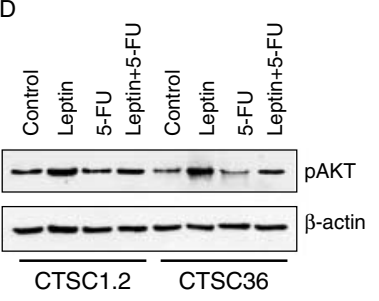

E
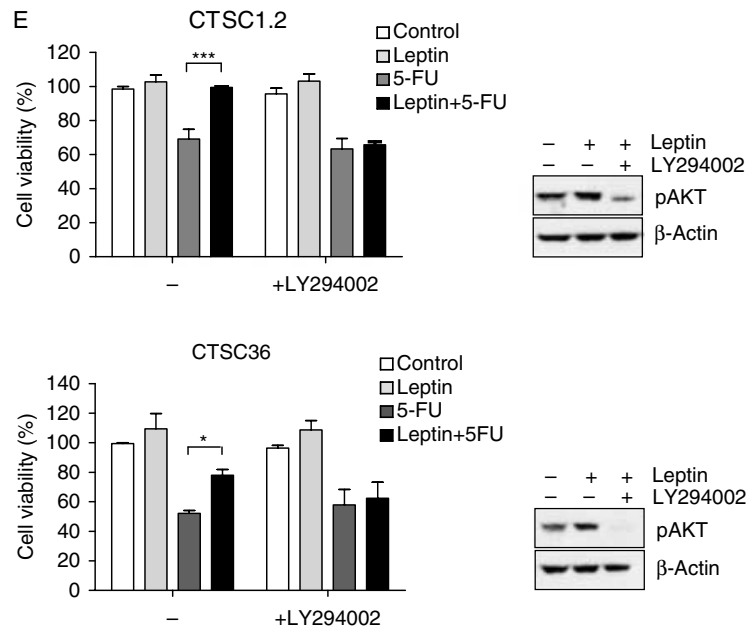

Figure 2 Leptin activates the PI3K/AKT signaling pathway and counteracts 5-FU-induced apoptosis in CTSCs. (A) Leptin-mediated activation of AKT was evaluated by western blotting, as described in Materials and methods. $\beta$-Actin levels were assessed as loading control. (B) Cell viability upon 5-FU treatment in the presence or in the absence of leptin was evaluated by direct cell counting, as described in Materials and methods. All data are a mean of three independent experiments. (C) Apoptosis in CTSCs treated with $5-F U$ in the presence or in the absence of leptin was assessed by TUNEL assay, as described in Materials and methods. Cells containing DNA strand breaks were stained with fluorescein-dUTP (red), and DAPI was used to visualize cell nuclei (blue).

(D) Activation of AKT in CTSCs was evaluated by western blotting, as described in Materials and methods. $\beta$-Actin levels were assessed as loading control. (E) Involvement of AKT in leptin-mediated protection from apoptosis was assessed using a PI3K inhibitor, LY294002. Cell viability and AKT expression and activation were determined as described in Materials and methods. $\beta$-Actin levels were assessed as loading control. 
Next experiments demonstrated that leptin counteracted the effects of 5-FU on a molecular level. Specifically, while 5-FU treatment reduced AKT activation in CTSCs, leptin partially or totally reversed this effect, suggesting that survival activity of leptin is mediated by AKT signaling (Fig. 2D). This possibility was addressed with the PI3K inhibitor LY294002 (Favata et al. 1998), which is known to block leptininduced AKT activation (Burguera et al. 2006, Sharma et al. 2006). Indeed, LY294002, at least in part, blocked leptin-dependent anti-apoptotic activity in 5-FU-treated CTSCs (Fig. 2E). However, leptin did not modulate ERK1/2 activity in the presence of 5-FU (data not shown), suggesting that this pathway is not involved in survival effects of ObR in our model.

\section{Leptin does not affect migration of CTSCs}

Enhanced cell migration is a feature associated with highly aggressive tumors (Attoub et al. 2000, Yamaguchi et al. 2005). Since leptin has been shown to promote migration and invasion of normal and cancer colon cells (Attoub et al. 2000, Jaffe \& Schwartz 2008, Ratke et al. 2010), we analyzed the possible effects of the hormone on CTSCs migration in vitro. We found that while leptin moderately induced CTSCs migration through the membranes, the effects were not statistically significant at all tested time points $(24,48$, and 96 h; Fig. $3 \mathrm{~A}$ and data not shown).

\section{Leptin promotes cell proliferation and colony forming ability}

Plasma leptin levels are proportional to body fat content, implicating that obese people are under chronic exposure to high circulating concentrations of this cytokine. In order to investigate the long-term impact of leptin on CTSCs, we carried out colonyforming assays in soft agar (Fig. 3B). We found that leptin significantly increased the number of colonies after 21 days of incubation. In addition, we observed a greater number of large aggregates and colonies in leptin-treated cultures relative to control. On the average, leptin exposure increased colony size from 210 to $250 \mu \mathrm{m}$ in CTSC36 cells, and from 280 to $290 \mu \mathrm{m}$ in CTSC1.2 cells, which might be related to enhanced cell-cell adhesion. Indeed, we observed upregulation of the cell adhesion protein E-cadherin in CTSC36, but not in CTSC1.2 (Fig. 3C). In addition, enhanced occurrence and larger size of aggregates and spheres could be observed when cells were cultured in normal medium supplemented with leptin (Fig. 3D).

\section{Discussion}

Cancer stem cells (CSCs) constitute a subpopulation of tumor cells that are selectively equipped with tumor initiation, self-renewal capacities, and the ability to give rise to bulk populations of nontumorigenic cancer cell through differentiation (Sabbath et al. 1985, Hanahan \& Weinberg 2000, Reya et al. 2001, Clarke et al. 2006, Morrison \& Kimble 2006). CSCs have been identified in several human malignancies, and their relative abundance in clinical cancer specimens has been correlated with disease progression (Arce et al. 2006, Schatton et al. 2008, Zhou et al. 2009). Understanding how CSCs interact with tumor environment, including circulating and locally produced cytokines and hormones, might impact clinical management of different cancer types and development of novel therapeutics.

The risk of colorectal cancer development is increased in obese individuals, possibly due to elevated activity of biologically active substances produced by the fat tissue (Pischon et al. 2008). The adipokine leptin has been implicated in colorectal cancer development and progression due to its mitogenic, anti-apoptotic, mitogenic, and pro-inflammatory activity (Garofalo \& Surmacz 2006, Karagiannides \& Pothoulakis 2007, Ratke et al. 2010). Here, we investigated, for the first time, the role of leptin in the biology of CTSCs. The characteristic stem cell features of CTSCs used in this study were described by us before (Ricci-Vitiani et al. 2007). Additionally, we confirmed in this paper that CTSC lines express several recognized markers of undifferentiated colorectal CSCs such as CD166 (Dalerba et al. 2007) and Lgr5 (Barker et al. 2007).

We found that all our CTSCs express different isoforms of $\mathrm{ObR}$; some clones express $\mathrm{ObR}$ at levels comparable with that detected in immortalized colon cancer cell lines. In CTSCs expressing higher levels of the long (signaling) form of ObR, leptin was able to induce cell growth and survival. Furthermore, in these clones, leptin activated the known growth/survival pathways, i.e. ERK1/2 and AKT (Balmanno \& Cook 2009, Engelman 2009, Huang \& Chen 2009). In addition, we found that in CTSCs, leptin can interfere with the efficacy of 5-FU, a commonly used colorectal cancer chemotherapeutic agent (Chung \& Saltz 2007, De Dosso et al. 2009), by ways of increasing cell viability and reducing 5-FU-inflicted DNA damage.

Experiments with specific inhibitors suggested that leptin-dependent growth in CTSCs relies principally on the ERK1/2 pathway, while leptin-mediated survival requires AKT signaling. Some of these effects 
A

CTSC36

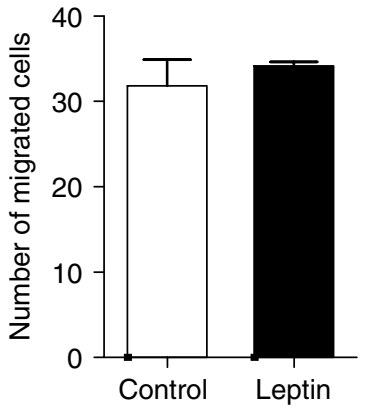

B

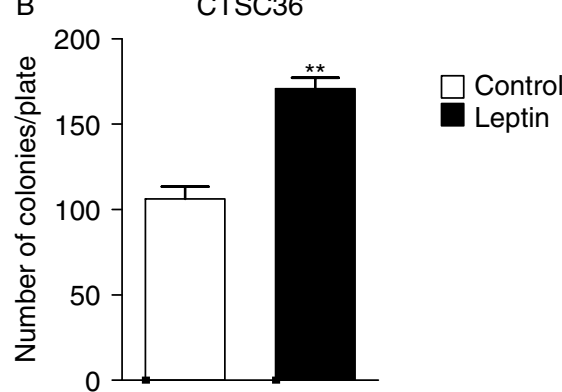

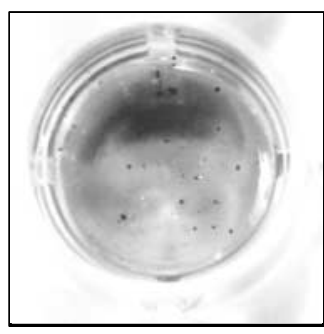

Control

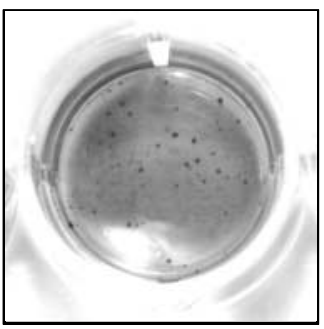

Leptin

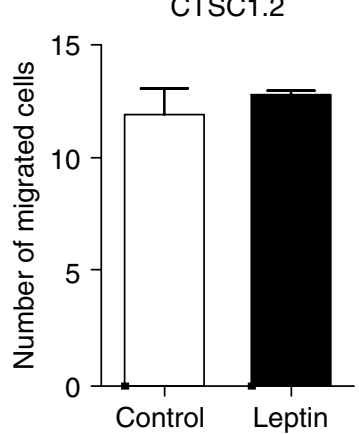

C

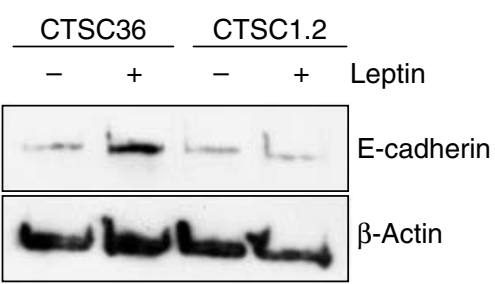

CTSC1.2

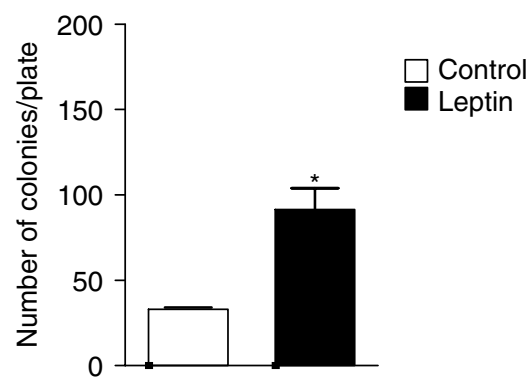

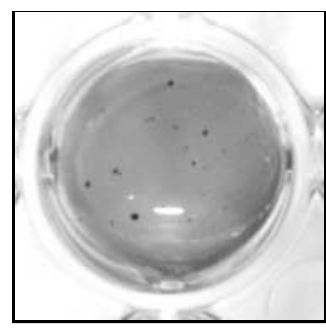

Control

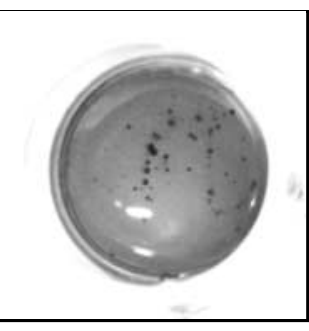

Leptin
D

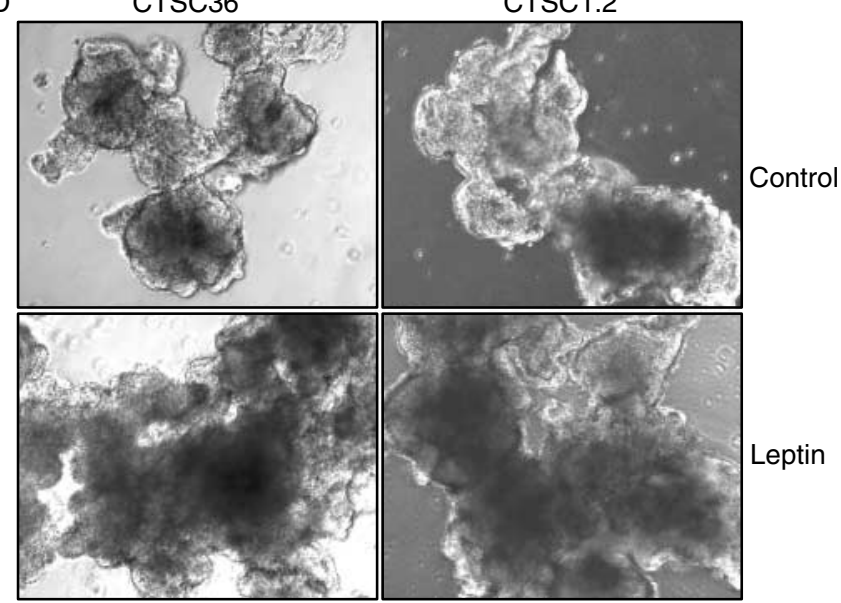

Figure 3 Leptin promotes colony forming ability and cell-cell adhesion of CTSCs. (A) Leptin effects on migration of CTSCs were evaluated as described in Materials and methods. (B) Effects of leptin on soft agar growth were determined in CTSCs as described in Materials and methods. The lower panel shows representative pictures of colonies. (C) Leptin-mediated effects on E-cadherin expression were determined by western blotting, as described in Materials and methods. $\beta$-Actin levels were assessed as loading control. (D) CTSCs were plated in normal culture medium with or without leptin, as described in Material and methods. CTSCs aggregation was documented using an Olympus IX81 inverted microscope equipped with an F-View monochrome camera, and representative pictures (magnification $10 \times$ ) are shown for each condition. 
might be related to increased expression of E-cadherin, a cell-cell adhesion protein that can be up-regulated by leptin in some cancer cells (Mauro et al. 2007) and promote anchorage-independent growth and survival (Steinberg \& McNutt 1999, Reddy et al. 2005). In line with this hypothesis, we observed that leptin addition increased E-cadherin expression, colony forming ability of CTSCs as well as cell-cell adhesion, especially in one of the clones expressing high levels of ObR.

In different colon cancer cell lines, leptin has been shown to promote migration and invasion through multiple pathways (Jaffe \& Schwartz 2008, Ratke et al. 2010). We, however, did not observe substantially increased migratory activity of CTSCs, even after long exposure to leptin $(300 \mathrm{ng} / \mathrm{ml})$. This discrepancy might result from the particulars of our experimental system. Namely, CTSCs naturally and readily form spheres in culture, which in turn prevents their dispersal and migration. The propensity of CTSCs to form aggregates could be additionally potentiated by E-cadherin overexpression in leptin-treated cultures.

In summary, our results suggest that leptin, a cytokine that is normally increased in overweight and obese individuals, can affect the growth and survival of CTSCs, promoting colorectal carcinogenesis and/or potentially interfere with chemotherapy. Since CSCtargeted approaches might represent translationally relevant strategies to improve clinical outcome, especially for those malignancies that are refractory to conventional anticancer agents directed at bulk tumor cell populations, interfering with leptin signaling by targeting ObR might become a novel attractive option for colorectal cancer treatment, especially in obese patients.

\section{Declaration of interest}

The authors declare that there is no conflict of interest that could be perceived as prejudicing the impartiality of the research reported.

\section{Funding}

This work was supported by funding from the Italian Association for Cancer Research and the Sbarro Health Research Organization.

\section{Acknowledgements}

We are grateful to Giuseppe Loreto for his assistance with figure editing.

\section{References}

Adeyemi EO, Bastaki SA, Chandranath IS, Hasan MY, Fahim M \& Adem A 2005 Mechanisms of action of leptin in preventing gastric ulcer. World Journal of Gastroenterology 11 4154-4160.

Ahima RS \& Osei SY 2004 Leptin signaling. Physiology and Behavior 81 223-241. (doi:10.1016/j.physbeh.2004.02. 014)

Amemori S, Ootani A, Aoki S, Fujise T, Shimoda R, Kakimoto T, Shiraishi R, Sakata Y, Tsunada S, Iwakiri R et al. 2007 Adipocytes and preadipocytes promote the proliferation of colon cancer cells in vitro. American Journal of Physiology. Gastrointestinal and Liver Physiology 292 G923-G929. (doi:10.1152/ajpgi. 00145.2006)

Aparicio T, Guilmeau S, Goiot H, Tsocas A, Laigneau JP, Bado A, Sobhani I \& Lehy T 2004 Leptin reduces the development of the initial precancerous lesions induced by azoxymethane in the rat colonic mucosa. Gastroenterology 126 499-510. (doi:10.1053/j.gastro.2003.11.004)

Aparicio T, Kermorgant S, Darmoul D, Guilmeau S, Hormi K, Mahieu-Caputo D \& Lehy T $2005 a$ Leptin and Ob-Rb receptor isoform in the human digestive tract during fetal development. Journal of Clinical Endocrinology and Metabolism 90 6177-6184. (doi:10.1210/jc.2005-1498)

Aparicio T, Kotelevets L, Tsocas A, Laigneau JP, Sobhani I, Chastre E \& Lehy T $2005 b$ Leptin stimulates the proliferation of human colon cancer cells in vitro but does not promote the growth of colon cancer xenografts in nude mice or intestinal tumorigenesis in Apc $(\mathrm{Min} /+)$ mice. Gut 54 1136-1145. (doi:10.1136/gut.2004.060533)

Arce C, Perez-Plasencia C, Gonzalez-Fierro A, de la CruzHernandez E, Revilla-Vazquez A, Chavez-Blanco A, Trejo-Becerril C, Perez-Cardenas E, Taja-Chayeb L, Bargallo E et al. 2006 A proof-of-principle study of epigenetic therapy added to neoadjuvant doxorubicin cyclophosphamide for locally advanced breast cancer. PLoS ONE 1 e98. (doi:10.1371/journal.pone.0000098)

Attoub S, Noe V, Pirola L, Bruyneel E, Chastre E, Mareel M, Wymann MP \& Gespach C 2000 Leptin promotes invasiveness of kidney and colonic epithelial cells via phosphoinositide 3-kinase-, rho-, and rac-dependent signaling pathways. FASEB Journal 14 2329-2338. (doi:10.1096/fj.00-0162)

Balmanno K \& Cook SJ 2009 Tumour cell survival signalling by the ERK1/2 pathway. Cell Death and Differentiation 16 368-377. (doi:10.1038/cdd.2008.148)

Barker N, van Es JH, Kuipers J, Kujala P, van den Born M, Cozijnsen M, Haegebarth A, Korving J, Begthel H, Peters PJ et al. 2007 Identification of stem cells in small intestine and colon by marker gene Lgr5. Nature 449 1003-1007. (doi:10.1038/nature06196)

Barker N, Ridgway RA, van Es JH, van de Wetering M, Begthel H, van den Born M, Danenberg E, Clarke AR, Sansom OJ \& Clevers H 2009 Crypt stem cells as the cells-of-origin of intestinal cancer. Nature 457 608-611. (doi:10.1038/nature07602) 
Bozkurt A, Cakir B, Ercan F \& Yegen BC 2003 Antiinflammatory effects of leptin and cholecystokinin on acetic acid-induced colitis in rats: role of capsaicinsensitive vagal afferent fibers. Regulatory Peptides 116 109-118. (doi:10.1016/S0167-0115(03)00194-0)

Burguera B, Brunetto A, Garcia-Ocana A, Teijeiro R, Esplen J, Thomas T, Couce ME \& Zhao A 2006 Leptin increases proliferation of human steosarcoma cells through activation of PI(3)-K and MAPK pathways. Medical Science Monitor 12 BR341-BR349.

Cakir B, Bozkurt A, Ercan F \& Yegen BC 2004 The antiinflammatory effect of leptin on experimental colitis: involvement of endogenous glucocorticoids. Peptides $\mathbf{2 5}$ 95-104. (doi:10.1016/j.peptides.2003.11.005)

Calle EE \& Thun MJ 2004 Obesity and cancer. Oncogene 23 6365-6378. (doi:10.1038/sj.onc.1207751)

Chung KY \& Saltz LB 2007 Adjuvant therapy of colon cancer: current status and future directions. Cancer Journal 13 192-197. (doi:10.1097/PPO.0b013e318074d26e)

Clarke MF, Dick JE, Dirks PB, Eaves CJ, Jamieson CH, Jones DL, Visvader J, Weissman IL \& Wahl GM 2006 Cancer stem cells - perspectives on current status and future directions: AACR Workshop on cancer stem cells. Cancer Research 66 9339-9344. (doi:10.1158/00085472.CAN-06-3126)

Dalerba P, Dylla SJ, Park IK, Liu R, Wang X, Cho RW, Hoey T, Gurney A, Huang EH, Simeone DM et al. 2007 Phenotypic characterization of human colorectal cancer stem cells. PNAS 104 10158-10163. (doi:10.1073/pnas. 0703478104)

De Dosso S, Sessa C \& Saletti P 2009 Adjuvant therapy for colon cancer: present and perspectives. Cancer Treatment Reviews 35 160-166. (doi:10.1016/j.ctrv.2008.10.001)

Engelman JA 2009 Targeting PI3K signalling in cancer: opportunities, challenges and limitations. Nature Reviews. Cancer 9 550-562. (doi:10.1038/nrc2664)

Favata MF, Horiuchi KY, Manos EJ, Daulerio AJ, Stradley DA, Feeser WS, Van Dyk DE, Pitts WJ, Earl RA, Hobbs F et al. 1998 Identification of a novel inhibitor of mitogenactivated protein kinase kinase. Journal of Biological Chemistry 273 18623-18632. (doi:10.1074/jbc.273.29. 18623)

Fenton JI, Hursting SD, Perkins SN \& Hord NG 2007 Leptin induces an Apc genotype-associated colon epithelial cell chemokine production pattern associated with macrophage chemotaxis and activation. Carcinogenesis 28 455-464. (doi:10.1093/carcin/bg1137)

Fenton JI, Lavigne JA, Perkins SN, Liu H, Chandramouli GV, Shih JH, Hord NG \& Hursting SD 2008 Microarray analysis reveals that leptin induces autocrine/paracrine cascades to promote survival and proliferation of colon epithelial cells in an Apc genotype-dependent fashion. Molecular Carcinogenesis 47 9-21. (doi:10.1002/mc. 20357)

Fruhbeck G 2006 Intracellular signalling pathways activated by leptin. Biochemical Journal 393 7-20. (doi:10.1042/ BJ20051578)
Garofalo C \& Surmacz E 2006 Leptin and cancer. Journal of Cellular Physiology 207 12-22. (doi:10.1002/jcp.20472)

Hanahan D \& Weinberg RA 2000 The hallmarks of cancer. Cell 100 57-70. (doi:10.1016/S0092-8674(00)81683-9)

Hardwick JC, Van Den Brink GR, Offerhaus GJ, Van Deventer SJ \& Peppelenbosch MP 2001 Leptin is a growth factor for colonic epithelial cells. Gastroenterology 121 79-90. (doi:10.1053/gast.2001.25490)

Huang XF \& Chen JZ 2009 Obesity, the PI3K/Akt signal pathway and colon cancer. Obesity Reviews 10 610-616. (doi:10.1111/j.1467-789X.2009.00607.x)

Jaffe T \& Schwartz B 2008 Leptin promotes motility and invasiveness in human colon cancer cells by activating multiple signal-transduction pathways. International Journal of Cancer 123 2543-2556. (doi:10. 1002/ijc.23821)

Jemal A, Siegel R, Ward E, Murray T, Xu J, Smigal C \& Thun MJ 2006 Cancer statistics, 2006. CA: A Cancer Journal for Clinicians 56 106-130. (doi:10.3322/canjclin. 56.2.106)

Karagiannides I \& Pothoulakis C 2007 Obesity, innate immunity and gut inflammation. Current Opinion in Gastroenterology 23 661-666. (doi:10.1097/MOG. 0b013e3282c8c8d3)

Koda M, Sulkowska M, Kanczuga-Koda L, Cascio S, Colucci G, Russo A, Surmacz E \& Sulkowski S 2007a Expression of the obesity hormone leptin and its receptor correlates with hypoxia-inducible factor- $1 \alpha$ in human colorectal cancer. Annals of Oncology 18 (Supplement 6) vi116-vi119. (doi:10.1093/annonc/mdm238)

Koda M, Sulkowska M, Kanczuga-Koda L, Surmacz E \& Sulkowski S 2007b Overexpression of the obesity hormone leptin in human colorectal cancer. Journal of Clinical Pathology 60 902-906. (doi:10.1136/jcp.2006. 041004)

Mauro L, Catalano S, Bossi G, Pellegrino M, Barone I, Morales S, Giordano C, Bartella V, Casaburi I \& Ando S 2007 Evidences that leptin up-regulates E-cadherin expression in breast cancer: effects on tumor growth and progression. Cancer Research 67 3412-3421. (doi:10. 1158/0008-5472.CAN-06-2890)

Morrison SJ \& Kimble J 2006 Asymmetric and symmetric stem-cell divisions in development and cancer. Nature 441 1068-1074. (doi:10.1038/nature04956)

O'Brien CA, Pollett A, Gallinger S \& Dick JE 2007 A human colon cancer cell capable of initiating tumour growth in immunodeficient mice. Nature 445 106-110. (doi:10. 1038/nature05372)

Ozes ON, Mayo LD, Gustin JA, Pfeffer SR, Pfeffer LM \& Donner DB 1999 NF- $\kappa$ B activation by tumour necrosis factor requires the Akt serine-threonine kinase. Nature 401 82-85. (doi:10.1038/43466)

Paik SS, Jang SM, Jang KS, Lee KH, Choi D \& Jang SJ 2009 Leptin expression correlates with favorable clinicopathologic phenotype and better prognosis in colorectal adenocarcinoma. Annals of Surgical Oncology 16 297-303. (doi:10.1245/s10434-008-0221-7) 
Pais R, Silaghi H, Silaghi AC, Rusu ML \& Dumitrascu DL 2009 Metabolic syndrome and risk of subsequent colorectal cancer. World Journal of Gastroenterology 15 5141-5148. (doi:10.3748/wjg.15.5141)

Pischon T, Nothlings U \& Boeing H 2008 Obesity and cancer. Proceedings of the Nutrition Society 67 128-145. (doi:10.1017/S0029665108006976)

Ratke J, Entschladen F, Niggemann B, Zanker KS \& Lang K 2010 Leptin stimulates the migration of colon carcinoma cells by multiple signaling pathways. Endocrine-Related Cancer 17 179-189. (doi:10.1677/ERC-09-0225)

Reddy P, Liu L, Ren C, Lindgren P, Boman K, Shen Y, Lundin E, Ottander U, Rytinki M \& Liu K 2005 Formation of E-cadherin-mediated cell-cell adhesion activates AKT and mitogen activated protein kinase via phosphatidylinositol 3 kinase and ligand-independent activation of epidermal growth factor receptor in ovarian cancer cells. Molecular Endocrinology 19 2564-2578. (doi:10.1210/me.2004-0342)

Renehan AG, Tyson M, Egger M, Heller RF \& Zwahlen M 2008 Body-mass index and incidence of cancer: a systematic review and meta-analysis of prospective observational studies. Lancet 371 569-578. (doi:10.1016/ S0140-6736(08)60269-X)

Reya T, Morrison SJ, Clarke MF \& Weissman IL 2001 Stem cells, cancer, and cancer stem cells. Nature 414 105-111. (doi:10.1038/35102167)

Ricci-Vitiani L, Lombardi DG, Pilozzi E, Biffoni M, Todaro M, Peschle C \& De Maria R 2007 Identification and expansion of human colon-cancer-initiating cells. Nature 445 111-115. (doi:10.1038/nature05384)

Ricci-Vitiani L, Fabrizi E, Palio E \& De Maria R 2009 Colon cancer stem cells. Journal of Molecular Medicine $\mathbf{8 7}$ 1097-1104. (doi:10.1007/s00109-009-0518-4)

Rouet-Benzineb P, Aparicio T, Guilmeau S, Pouzet C, Descatoire V, Buyse M \& Bado A 2004 Leptin counteracts sodium butyrate-induced apoptosis in human colon cancer HT-29 cells via NF- $\kappa \mathrm{B}$ signaling. Journal of Biological Chemistry 279 16495-16502. (doi:10.1074/ jbc.M312999200)

Sabbath KD, Ball ED, Larcom P, Davis RB \& Griffin JD 1985 Heterogeneity of clonogenic cells in acute myeloblastic leukemia. Journal of Clinical Investigation $\mathbf{7 5}$ 746-753. (doi:10.1172/JCI111756)

Sato T, Vries RG, Snippert HJ, van de Wetering M, Barker N, Stange DE, van Es JH, Abo A, Kujala P, Peters PJ et al. 2009 Single Lgr5 stem cells build crypt-villus structures in vitro without a mesenchymal niche. Nature 459 262-265. (doi:10.1038/nature07935)

Schatton T, Murphy GF, Frank NY, Yamaura K, WaagaGasser AM, Gasser M, Zhan Q, Jordan S, Duncan LM, Weishaupt C et al. 2008 Identification of cells initiating human melanomas. Nature 451 345-349. (doi:10.1038/ nature06489)
Sharma D, Saxena NK, Vertino PM \& Anania FA 2006 Leptin promotes the proliferative response and invasiveness in human endometrial cancer cells by activating multiple signal-transduction pathways. EndocrineRelated Cancer 13 629-640. (doi:10.1677/erc.1.01169)

Siegmund B, Lehr HA \& Fantuzzi G 2002 Leptin: a pivotal mediator of intestinal inflammation in mice. Gastroenterology 122 2011-2025. (doi:10.1053/gast. 2002.33631)

Siegmund B, Sennello JA, Lehr HA, Batra A, Fedke I, Zeitz M \& Fantuzzi G 2004 Development of intestinal inflammation in double IL-10- and leptin-deficient mice. Journal of Leukocyte Biology 76 782-786. (doi:10.1189/ jlb.0404239)

Sitaraman S, Liu X, Charrier L, Gu LH, Ziegler TR, Gewirtz A \& Merlin D 2004 Colonic leptin: source of a novel proinflammatory cytokine involved in IBD. FASEB Journal 18 696-698. (doi:10.1096/fj.03-0422fje)

Stattin P, Palmqvist R, Soderberg S, Biessy C, Ardnor B, Hallmans G, Kaaks R \& Olsson T 2003 Plasma leptin and colorectal cancer risk: a prospective study in Northern Sweden. Oncology Reports 10 2015-2021.

Stattin P, Lukanova A, Biessy C, Soderberg S, Palmqvist R, Kaaks R, Olsson T \& Jellum E 2004 Obesity and colon cancer: does leptin provide a link? International Journal of Cancer 109 149-152. (doi:10.1002/ijc.11668)

Steinberg MS \& McNutt PM 1999 Cadherins and their connections: adhesion junctions have broader functions. Current Opinion in Cell Biology 11 554-560. (doi:10. 1016/S0955-0674(99)00027-7)

Wauters M, Considine RV \& Van Gaal LF 2000 Human leptin: from an adipocyte hormone to an endocrine mediator. European Journal of Endocrinology 143 293-311. (doi:10.1530/eje.0.1430293)

Wilmink AB 1997 Overview of the epidemiology of colorectal cancer. Diseases of the Colon and Rectum 40 483-493. (doi:10.1007/BF02258397)

Yamaguchi H, Wyckoff J \& Condeelis J 2005 Cell migration in tumors. Current Opinion in Cell Biology 17 559-564. (doi:10.1016/j.ceb.2005.08.002)

Yang J, Liu X, Bhalla K, Kim CN, Ibrado AM, Cai J, Peng TI, Jones DP \& Wang X 1997 Prevention of apoptosis by Bcl-2: release of cytochrome $c$ from mitochondria blocked. Science 275 1129-1132. (doi:10.1126/science. 275.5303.1129)

Zhang F, Chen Y, Heiman M \& Dimarchi R 2005 Leptin: structure, function and biology. Vitamins and Hormones 71 345-372. (doi:10.1016/S0083-6729 (05)71012-8)

Zhou BB, Zhang H, Damelin M, Geles KG, Grindley JC \& Dirks PB 2009 Tumour-initiating cells: challenges and opportunities for anticancer drug discovery. Nature Reviews. Drug Discovery 8 806-823. (doi:10.1038/ $\operatorname{nrd2137)}$ 